Original article

Paediatrics Today 2014;10(2):135-146

DOI $10.5457 / \mathrm{p} 2005-114.99$

\title{
NATIONWIDE STUDY ON CHILDREN AND ADOLESCENTS IN FOSTER CARE IN BRAZIL
}

\author{
Simone GONÇALVES DE ASSIS, Liana WERNERSBACH PINTO, Joviana QUINTES AVANCI
}

Latin American Center of Studies on Violence and Health, National School of Public Health, Oswaldo Cruz Foundation Rio de Janeiro, Brazil

\author{
Corresponding author: \\ Simone Gonçalves de Assis \\ Avenida Brasil 4036/700 \\ Manguinhos \\ 21040-361 Rio de Janeiro, RJ, Brasil \\ simone@claves.fiocruz.br \\ Tel.: + 552138829155 \\ Fax.: + 552122900387
}

Received: May 16, 2014

Accepted: August 6, 2014

Copyright (C) 2014 by University Clinical Centre Tuzla. E-mail for permission to publish: paediatricstoday@ukctuzla.ba

\begin{abstract}
Objective - To present data from the first nationwide study on children and adolescents in foster care (institutional care and family care services) in Brazil. It seeks to provide a profile of these institutions, the number of children and adolescents in foster care, the context of the services and the reason the child/adolescent was taken in, set against the population size (small, medium, large, and metropolises) of the municipality where the institution is located. The study also describes the general health conditions of the children and adolescents living in foster care. Materials and methods - Data from 2,617 institutional care and 144 family care units spread across 1,157 Brazilian municipalities are presented. Results - The number of children and adolescents assisted was 37,861, of whom 36,929 were in institutional care services and 932 in family care services. Most children and adolescents in institutional care were located in large municipalities and metropolises $(65.4 \%)$, while those in family care are more likely to be in small municipalities. The most frequent reasons for taking in the children and adolescents were neglect and abandonment. A total of $7.6 \%$ of the children and adolescents in institutional care services and $7.7 \%$ of those in family care services were found to have health problems, the most significant being mental health issues, infectious diseases and genetic and congenital diseases. Conclusion - The study provides a better understanding of the situation of children and adolescents in foster care and the associated problems, particularly in developing countries, thereby providing suggestions for the planning and enforcement of public policies aimed at the protection of young people.
\end{abstract}

Key words: Foster care • Child • Adolescent.

\section{Introduction}

Many children and adolescents live in foster care around the world, a temporary service intended to address rights violations that have led to the child or adolescent leaving their family or community surroundings. These children and adolescents may live with unrelated foster parents, with relatives, with families who plan to adopt them, or in group homes or residential centers.
The magnitude of the problem is varied and little known in many countries, particularly in developing countries. National surveys in Brazil are recent, and show that between 2009 and 2010, there were 36,929 children and adolescents in residential care institutions and 932 in family care (1), while for the period 2012 to 2013 , these numbers were 29,321 and 1,019 , respectively (2). In Spain, the first study based on national data reported that on 31 December 2002, there 
were 14,211 individuals in large residential care institutions (45.3\%), 14,670 (46.8\%) in kinship care (with relatives), and 2,487 $(7.9 \%)$ in nonkinship care (with unrelated foster parents) (3). The United States has a historical record of the statistics of care, showing a significant growth rate. Between 2002 and 2012, the foster care population declined by almost a quarter (from 523,616 to 399,546) and experienced a shift in its racial and ethnic composition, with a significant reduction in the number of black or African American children in care (4). Kinship care is widely used in the U.S. foster care system.

The statistics reflect the public policies introduced in these countries over the past decades, with a rise of family-centered, familyfocused, and family-based models, addressing the needs and welfare of children within the context of their families and communities. In Brazil, from 1990 onwards the legislation that regulates care services towards children and adolescents separated from their families underwent a change. It began to place a greater emphasis on being surrounded by family and community, a shift away from the historical tendency of family institutionalization and exclusion.

There are different systems and classifications of foster care around the world and the limited access to international publications in some developed countries prevents a broader understanding of the topic. Moreover, there is a lack of information regarding regional or locally specific facts, since a large proportion of existing publications refer to the harmful effects that foster care may have on children and adolescents.

This article draws on the first national survey conducted in Brazil on children and adolescents in foster care (institutional care and family care), which was carried out in 2009-2010. The survey occurred at a time of change in the care provided to institutionalized children and adolescents in Brazil, with a shift towards ensuring the right to live close to family and community. The Unified System for Social Services was created and several regulations were put in place regarding the services provided to children and adolescents in foster care, with the aim of prioritizing family and community life. In addition, efforts were made to standardize the Brazilian institutional care modalities, including: (a) shelters, defined in legislation as care provided in institutional units similar to a residence, intended to assist groups of up to 20 children and/or adolescents, with educators/ caregivers working in daily fixed shifts; (b) residence-homes, which offer care in residential units, where a person or a couple works as a resident educator/caregiver, providing care to a group of up to 10 children and/or adolescents; and (c) transition houses, which provide the first dwelling or an emergency residence for children and adolescents that have been abandoned, are at risk, or have suffered a violation of their rights, while their situation is diagnosed (5).

In addition, there is also family care, which in Brazil is overseen by professionals, with an intervention plan defined and managed by a service with links to public sector social services. This service selects, registers and trains the foster families, which must accept the child/adolescent in their family home, regardless of how long it takes. The foster families must respect the identity and background of the young person, providing them with basic care, as well as affection, love and guidance, and work towards their full development and inclusion in the family, as a mean of guaranteeing them family and community based life (5). The service is also responsible for following up with the activities and life of the child and/or adolescent and their family of origin.

In recent years, Brazil has undergone significant economic growth, particularly in the period from 2003 to 2008, with the draw- 
ing up of public policies focused on income growth and poverty. These changes are reflected in the improvements in the Human Development Index (HDI) that the country has experienced over the last few decades: between 1980 and 2011, the HDI rose from 0.549 to 0.718 , thereby ensuring Brazil's inclusion as a country with high human development rates. However, such data hides significant social disparities and a concentration of income amongst the most wealthy, with a Gini coefficient of 51.9 in 2012 (6). The global economic crisis of recent years has reduced the country's growth and had the most significant impact on the poorest, thereby imposing a greater burden on the most vulnerable families.

In Brazil, the social and economic differences between small, medium and large municipalities are stark. These differences can have an indirect impact on the health and well-being of children, adolescents and their families, as well as on the public investments designed to improve social protection and services. The smallest municipalities are typically also those with the lowest degrees of socioeconomic development, higher birth rates and lower levels of literacy; while the larger municipalities tend to display a greater degree of urbanization, rapid population growth and increases in poorer, urban outskirts. These sociodemographic characteristics are important elements in helping to understand the Brazilian foster care system. A U.S. study also highlights the importance of analyzing the foster care system from the perspective of town sizes, since smaller towns usually find it easier to implement public policies $(7,8)$.

This article therefore presents data from the first national survey carried out in Brazil and has the following aims: (a) to provide a profile of foster care, including the number of children and adolescents assisted, the context of the care provided and the reasons why children and adolescents are taken in, by population size (small, midsize, large mu- nicipalities, and metropolises); and (b) to describe the general health conditions of the children and adolescents living in foster care.

\section{Materials and methods}

In 2012, government administration in Brazil was distributed across 5,565 municipalities, 27 states and five regions (North, Northeast, Center West, Southeast and South). Classification of the municipalities by population size shows that $30.9 \%$ are small, (with up to 49,999 inhabitants), $12.1 \%$ are midsize (with between 50,000 and 99,999 inhabitants) and $33.0 \%$ are large, containing up to 899,999 inhabitants. The metropolises (626 cities with 900,000 inhabitants or more) are mostly concentrated in the South (21.1\%), and Southeast $(61.2 \%)$ regions of the country.

The data presented here comes from a survey entitled "National Survey of Children and Adolescents in Foster Care Services in Brazil' conducted in partnership by the Ministry of Social Development (MDS) and the Jorge Careli Latin American Center for Studies on Violence and Health (CLAVES) of the National School of Public Health (ENSP) at the Oswaldo Cruz Foundation (FIOCRUZ). The information was gathered between September 2009 and November 2010, resulting in data from 2,624 Institutional Foster Care Units, across 1,157 Brazilian cities in all 27 of the Brazilian states.

All foster care units in Brazil were visited, as the institutions were registered with the Ministry of Social Development and the National Council of Justice. Two types of questionnaires were applied: (a) one directed at the institution's director with the aim of gathering data about the service (including general identification information, profile of the director and the public who access the service, total number of children and adolescents, type of service offered, health conditions of the children and adolescents, information 
registry, organs/institutions that make up the network of care providers, human resources of the service and training of members of the team, among other information); and (b) another questionnaire, answered by the staff members directly responsible for looking after the children/adolescents, the aim of which was to collect data about each one of the children/adolescents in care (including general identification information about the child/adolescent, information about the care provided, the family and the children's and adolescents health condition, and about the family of origin. The staff members were advised to consult the children's and adolescents' records at this stage (2).

\section{Ethics statement}

The research was approved by the Committee for Ethics in Research at the National School of Public Health, FIOCRUZ (CAAE: 0035.0.031.000-09).

\section{Statistical analysis}

The research presented here is a descriptiveexploratory study. The statistical analysis involved the construction and description of the absolute and relative frequencies of all the variables collected. In addition, contingency tables were prepared, showing the absolute and relative frequencies of selected variables, according to the size of the municipality. SPSS 19 was used for data processing and analysis. The data was grouped according to the type of service, including institutional care (shelters and residence-homes, for example) and family care service (mainly unrelated foster parents, but also foster care provided by relatives).

\section{Results}

\section{Institutional care}

The analysis of 2,617 Brazilian institutional care units is presented in Table 1. Two mo- dalities of service stand out: shelters $(64.2 \%$ of the total) and residence-homes (17.5\%). Brazilian legislation describes other modalities and among these, transition houses were the most prevalent, along with shared houses, hospitals, and schools (18.3\%). All types of institutional care must encourage family and community life, and ensure access to equipment and services found in the local community.

Table 1 shows that the larger the municipality, the greater the predominance of shelters: $68.2 \%$ of foster care services are found in the metropolises. The residence-homes follow a similar trend, rising from $13.8 \%$ in small municipalities to $21.6 \%$ in metropolises. However, the transition homes show an inverse trend, as the number is higher in small municipalities (27.3\%), and decreases in metropolises (10.2\%).

Most of the services shown in Table 1 are located in the Southeast $(57.8 \%$ of the total) and South (20.6\%), the two wealthiest regions in Brazil. These regions are home to the largest Brazilian cities, accounting for $67 \%$ of the country's 273 large cities or metropolises. The remaining three regions have fewer institutional care units: $7.0 \%$ in the Center West, 3.7\% in the North, and $10.6 \%$ in the Northeast.

At the time of the study, 36,929 children and adolescents were in care in Brazilian institutional units. $60.8 \%$ of them are aged 11 or younger, $52.3 \%$ are male, $8.9 \%$ have some form of disability, $50.9 \%$ have black or brown skin color, $19.7 \%$ do not attend school, 17\% have lived on the streets, $66 \%$ are sheltered in the city in which their family lives, and $52.5 \%$ of them are visited at the institution.

The majority of children and adolescents in institutional care units $(65.4 \%$, Table 2$)$ are located in large cities and metropolises, while of the 55 million children and adolescents in Brazil, $52.1 \%$ of them are located in these major cities. Table 2 also shows that small size municipalities have a ratio of 0.04 
Table 1 Types of institutional care services in cities with different population sizes

\begin{tabular}{|c|c|c|c|c|c|}
\hline \multirow{3}{*}{ Type of unit } & \multicolumn{5}{|c|}{ Cities with different population sizes } \\
\hline & Small size & Mid size & Large size & Metropolis & Total \\
\hline & $(\mathrm{n}=809)$ & $(\mathrm{n}=317)$ & $(\mathrm{n}=865)$ & $(\mathrm{n}=626)$ & $(\mathrm{n}=2.617)$ \\
\hline Shelter $(\%)$ & 58.9 & 65.3 & 66 & 68.2 & 64.2 \\
\hline Residence-home (\%) & 13.8 & 14.8 & 19.1 & 21.6 & 17.5 \\
\hline Transition house/others (\%) & 27.3 & 19.9 & 14.9 & 10.2 & 18.3 \\
\hline
\end{tabular}

Table 2 Information on children and adolescents in institutional care units, according to population size Brazil

\begin{tabular}{llllll}
\hline \multirow{2}{*}{$\begin{array}{l}\text { Information on children, adolescents } \\
\text { and institutional care units }\end{array}$} & \multicolumn{4}{l}{ Cities with different population sizes } \\
\cline { 2 - 6 } & $\begin{array}{l}\text { Small } \\
\text { size (\%) }\end{array}$ & $\begin{array}{l}\text { Mid } \\
\text { size }(\%)\end{array}$ & $\begin{array}{l}\text { Large } \\
\text { size (\%) }\end{array}$ & $\begin{array}{l}\text { Metropolis } \\
(\%)\end{array}$ & $\begin{array}{l}\text { Total } \\
(\%)\end{array}$ \\
\hline $\begin{array}{l}\text { Per cent children and adolescents in } \\
\text { institutional care (Total: } \mathrm{n}=36,802)^{*}\end{array}$ & 22.4 & 12.2 & 37.6 & 27.8 & 100 \\
$\begin{array}{l}\text { Per cent of the Brazilian population between 0 and } 17 \\
\text { years old (total: } \mathrm{n}=54,716,401)\end{array}$ & 36.1 & 11.7 & 31.7 & 20.5 & 100 \\
$\begin{array}{l}\text { Ratio between of children/adolescents in institutional care } \\
\text { and total of children/adolescents }\end{array}$ & 0.04 & 0.07 & 0.08 & 0.09 & 0.07 \\
$\begin{array}{l}\text { Rate number of services of institutional care per 100,000 } \\
\text { children / adolescents }\end{array}$ & 4.09 & 4.94 & 5 & 5.59 & 4.78 \\
\hline
\end{tabular}

*199 Missing.

institutionalized children in comparison to the total population; this percentage grows gradually, as in the metropolises this ratio rises to 0.09 , pointing to a trend of entering institutional care in larger urban centers. Such a concentration can also be observed in the increase in rates of institutional care units in relation to the size of the population: small municipalities have 4.09 services per 100,000 inhabitants, while for metropolises, this figure is 5.59 .

Table 3 shows further data on institutional care in Brazil. In smaller cities government involvement in the running of institutions is greater, while in larger cities and metropolises, only $12.5 \%$ of shelters and residencehomes are government administered. Just over half of the institutional care services across the country $(51.3 \%)$ are run by religious organizations, with a slightly higher proportion in the metropolises $(54.8 \%)$. The most common religious affiliation is Catholic, followed by Protestant, Ecumenical and finally Spiritism. The Northeast region of the country holds the largest percentage of services with this feature (67\%) and the South (which is wealthier and has a greater number of people of European descent) holds the smallest percentage (43\%). In some states in the North and Northeast, all units have a religious affiliation.

About $78.4 \%$ of the institutional care service units were created in the last 20 years, already under a specific law (9), which has led to changes in the conditions of care provided to children and adolescents in Brazil. During this period, an even greater proportion of services were founded in small and midsize municipalities, where there are a higher proportion of government run institutions, pointing to recent public sector investment in social services. 
With regard to human resources, Brazilian legislation recommends the presence of two higher education professionals, namely a psychologist and a social worker in the units. Only $45.1 \%$ of the units meet this recommendation. The correct composition of the team is less likely to be found in small municipalities (35.1\%). Confirming the view that Brazilian institutional care units face significant human resource challenges, 25.1\% have just one of these professionals and $25.4 \%$ have neither (data not shown in Table 3 ). The legislation also requires two caregivers (usually with a high school education) for every 20 children in residential care. Table 3 shows that $63.8 \%$ of the service units have a caregiver in each shift for every 10 children. Table 3 further shows that $78.2 \%$ of the institutional care units meet the legal requirement of having up to 20 children/adolescents per unit, resulting in a more positive picture for institutions located in small municipalities $(88.8 \%)$.
The recommended number of children/ adolescents per room is up to four. However, only $42 \%$ of the units meet this requirement. The size comparison shows that approximately $52.4 \%$ of the services units located in small municipalities meet the recommendation, while only $32.1 \%$ in metropolises do. Around $11 \%$ of the service units have 10 or more children/adolescents per room.

The vast majority of service units (98.5\%) provide care for children/adolescents in vulnerable situations including those with mental disorders, mental retardation, speech and physical sensorial deficiencies, with contagious diseases, drug users, gays, lesbians or transvestites, or those that have lived in the streets or have received death threats. Regarding the care provided to pregnant adolescents, there was a significant difference between municipalities of different sizes: in metropolises, $32.1 \%$ of units reported providing care to this public, against $63.2 \%$ of units in small municipalities. A similar result

\section{Table 3 Characteristics of institutional care services}

\begin{tabular}{|c|c|c|c|c|c|}
\hline \multirow{4}{*}{ Information on institutional care units } & \multicolumn{5}{|c|}{ Cities with different population sizes } \\
\hline & $\begin{array}{l}\text { Small } \\
\text { size }\end{array}$ & $\begin{array}{l}\text { Mid } \\
\text { size }\end{array}$ & $\begin{array}{l}\text { Large } \\
\text { size }\end{array}$ & Metropolis & Total \\
\hline & $(\mathrm{n}=809)$ & $(\mathrm{n}=317)$ & $(\mathrm{n}=865)$ & $(\mathrm{n}=626)$ & $(\mathrm{n}=2,617)$ \\
\hline & $\%$ & $\%$ & $\%$ & $\%$ & $\%$ \\
\hline Government administration $^{1}$ & 49.4 & 38.8 & 29.6 & 12.5 & 34.7 \\
\hline Religion affiliation ${ }^{2}$ & 47.5 & 48.3 & 53.4 & 54.8 & 51.3 \\
\hline Operating time of service up to 20 years $^{2}$ & 84.5 & 79.5 & 75.3 & 73.6 & 78.4 \\
\hline Team composed of psychologist and social worker ${ }^{1}$ & 35.1 & 50 & 51.3 & 46.2 & 45.1 \\
\hline $\begin{array}{l}\text { Services with up to one caregiver/shift for every ten } \\
\text { children }^{3}\end{array}$ & 66.4 & 61.2 & 60.4 & 67 & 63.8 \\
\hline Service units with up to 20 children and adolescents ${ }^{2}$ & 88.8 & 76 & 72.4 & 73.5 & 78.2 \\
\hline Up to 4 children and adolescents by bedroom ${ }^{4}$ & 52.4 & 44.5 & 38.8 & 32.1 & 42 \\
\hline $\begin{array}{l}\text { Services that take children and adolescents in vulnerable } \\
\text { situations }{ }^{4}\end{array}$ & 98.7 & 99.6 & 99.5 & 96.5 & 98.5 \\
\hline $\begin{array}{l}\text { Services with accessibility for children and adolescents } \\
\text { with disabilities }{ }^{2}\end{array}$ & 10.8 & 17.7 & 16.8 & 16.9 & 15 \\
\hline
\end{tabular}

${ }^{1} \mathrm{n}=2,279$ (small size $=680$; mid-size $=258$; large size $=774$; metropolis $\left.=567\right) ;{ }^{2} \mathrm{n}=2,617$ (small size=809; mid-size $=317$; large size= 865; metropolis $=626$ ); ${ }^{3} \mathrm{n}=1,709$ (small size $=470$; mid-size $=206$; large size $=606$; metropolis $=427$ ); ${ }^{4} \mathrm{n}=2,269$ (small size $=672$; midsize $=258$; large size $=774$; metropolis $=65$ ). 
was found for adolescents who have children, which can be more difficult in small towns (data not shown).

Regarding accessibility for children and adolescents with disabilities, the units were far from meeting the requirements set out in Brazilian legislation: only 15\% of Brazilian services complied with such legislation (and only $10.8 \%$ of units in small municipalities did so).

Concerning the length of permanency in institutional care units, Brazilian legislation limits this period to 24 months. $69.6 \%$ $(\mathrm{n}=25,139)$ of institutions across the country reported being within the legal time frame. In the metropolises, the situation is slightly worse $(66.8 \%)$, while in midsize municipalities, the scenario is more positive $(73.0 \%)$. The remaining municipalities are consistent with the national average (70\%).

\section{Principal reasons for seeking care, by population size}

The most frequent reasons why children and adolescents seek shelter in institutional care are: negligence $(33.2 \%)$, whereby parents or guardians are unable to provide basic needs that guarantee the physical, emotional and social development of the child or adolescent, such as hygiene issues and a failure to guarantee basic health or education rights; abandonment (18.5\%), considered the most serious form of negligence, where the parent or guardian has partially or fully exposed the child/adolescent to a situation involving abandonment or danger; parents or guardians who are chemical dependents or alcoholics $(17.7 \%)$; and families in which the child or adolescent has been subjected to physical violence by them (9.6\%).

When comparing the reasons for sheltering the child or adolescent by municipality size, as the population increases, there is a gradual increase in the number of children and adolescents taken in, since they are more likely to be found in the streets in larger conurbations. This percentage reaches its maximum $(12.2 \%)$ in the metropolises. An inverse situation takes place in situations in which the child or adolescent has been given shelter as a result of chemical dependence of parents or guardians, as rates of such cases increase as the population size of the mu-

\section{Table 4 Top five reasons for institutional care*}

\begin{tabular}{|c|c|c|c|c|}
\hline \multirow{2}{*}{$\begin{array}{l}\text { Reasons for } \\
\text { foster care }\end{array}$} & \multicolumn{4}{|c|}{ Cities with different population sizes } \\
\hline & Small size & Mid size & Large size & Metropolis \\
\hline 1 & $\begin{array}{l}\text { Negligence in the family } \\
(35.0 \%)\end{array}$ & $\begin{array}{l}\text { Negligence in the family } \\
(34.2 \%)\end{array}$ & $\begin{array}{l}\text { Negligence in the family } \\
(32.9 \%)\end{array}$ & $\begin{array}{l}\text { Negligence in the family } \\
(32.2 \%)\end{array}$ \\
\hline 2 & $\begin{array}{l}\text { Parents or guardians are } \\
\text { chemically addicted/ } \\
\text { alcoholics }(19.2 \%)\end{array}$ & $\begin{array}{l}\text { Abandonment by parents } \\
\text { or guardians }(18.7 \%)\end{array}$ & $\begin{array}{l}\text { Abandonment by parents } \\
\text { or guardians }(18.1 \%)\end{array}$ & $\begin{array}{l}\text { Abandonment by parents } \\
\text { or guardians }(18.8 \%)\end{array}$ \\
\hline 3 & $\begin{array}{l}\text { Abandonment by parents } \\
\text { or guardians }(18.7 \%)\end{array}$ & $\begin{array}{l}\text { Parents or guardians are } \\
\text { chemically addicted/ } \\
\text { alcoholics }(18.5 \%)\end{array}$ & $\begin{array}{l}\text { Parents or guardians are } \\
\text { chemically addicted/ } \\
\text { alcoholics }(17.7 \%)\end{array}$ & $\begin{array}{l}\text { Parents or guardians are } \\
\text { chemically addicted/ } \\
\text { alcoholics }(16.5 \%)\end{array}$ \\
\hline 4 & $\begin{array}{l}\text { Family physical violence } \\
\text { against the children/ } \\
\text { adolescent }(10.0 \%)\end{array}$ & $\begin{array}{l}\text { Family physical violence } \\
\text { against the children/ } \\
\text { adolescent }(9.0 \%)\end{array}$ & $\begin{array}{l}\text { Family physical violence } \\
\text { against the children/ } \\
\text { adolescent }(9.2 \%)\end{array}$ & $\begin{array}{l}\text { Living in } \\
\text { the streets }(12.2 \%)\end{array}$ \\
\hline 5 & $\begin{array}{l}\text { Lack of material resources } \\
\text { in the family }(8.7 \%)\end{array}$ & $\begin{array}{l}\text { Living in the streets } \\
(7.7 \%)\end{array}$ & $\begin{array}{l}\text { Living in the streets } \\
(8.6 \%)\end{array}$ & $\begin{array}{l}\text { Lack of material resources } \\
\text { in the family }(11.5 \%)\end{array}$ \\
\hline
\end{tabular}

*The percentages do not total $100 \%$. Frequently, there is more than one reason justifying foster care. Also, there are other reasons not shown (less frequent). 
nicipality decreases. In this case, the highest percentage is found in small municipalities (19.5\%).

\section{Health conditions of children and adolescents in institutional care services}

A total of $7.6 \%$ of children and adolescents receiving care in institutional services were found to have health problems, with a predominance in the North and South of the country. The most significant problems were mental health problems $(31.1 \%)$, infectious diseases $(20.5 \%)$ and genetic and congenital diseases (19.4\%). In family care services, $7.7 \%$ of children and adolescents had health problems, with a greater concentration in the North, Northeast and Center West regions. For this group, the most common issues were mental health problems (40.6\%), followed by genetic and congenital diseases (34.7\%) and infectious diseases (33.3\%).

\section{Family care service}

In the majority of Brazilian municipalities, kinship care is not considered a public policy. The following data is therefore mostly related to the non-relative foster care model.

In Brazil, there are 144 family care services, of which $60.4 \%$ are located in small municipalities, $8.3 \%$ in midsize ones, $19.4 \%$ in large cities, and $11.8 \%$ in metropolises (Table 5). Family care services are a new phenomenon (the oldest such service in the country was 16 years old at the time of the study) and are still not widely used in Brazil, where they are mostly concentrated in the South and Southeast regions (accounting for $92.8 \%$ of the children and adolescents taken in). About $60.5 \%$ of the existing services in the country had been operating for four years or less. In small, midsize and large municipalities, services that had been functioning for four years or less, represented respectively, $51.5 \%, 62.5 \%$ and $65.2 \%$ of all family care services. In the metropolises, this figure was highest (88.2\%, Table 5). In small municipalities, $95.4 \%$ of these services are run by the state, while this is the case in $75 \%$ of those located in large municipalities.

Family care services in Brazil provide assistance to 932 children and adolescents. $25.8 \%$ of these services are found in small municipalities, $6.1 \%$ in midsize municipalities, and $68.1 \%$ are in large municipalities or metropolises. $61.8 \%$ of children and adolescents are aged 11 or younger, $50.8 \%$ are male, $7.6 \%$ have some type of disability, $55.6 \%$ have black or brown skin color, $14.4 \%$ do not attend school, $15.6 \%$ have lived in the streets, $83.3 \%$ are sheltered in the same city in which their family live, and $52.5 \%$ of them are visited at the institution. Regarding the time spent in foster care, $68.5 \%$ spend up to 24 months. This percentage ranged between $61.6 \%$ (small municipalities) and 94.7\% (large ones).

Concerning the reasons that led the child or adolescent to foster care, negligence was

\section{Table 5 Characteristics of family care services}

\begin{tabular}{|c|c|c|c|c|c|}
\hline \multirow{3}{*}{$\begin{array}{l}\text { Information on } \\
\text { foster family care }\end{array}$} & \multicolumn{5}{|c|}{ Cities with different population sizes } \\
\hline & Small size & Midsize & Large size & Metropolis & Total \\
\hline & $(\mathrm{n}=87)$ & $(\mathrm{n}=12)$ & $(\mathrm{n}=8)$ & $(\mathrm{n}=17)$ & $(\mathrm{n}=144)$ \\
\hline Family care services (\%) & 60.4 & 8.3 & 19.4 & 11.8 & 100 \\
\hline Government administration (\%) & 95.4 & 91.7 & 75 & 94.1 & 91 \\
\hline $\begin{array}{l}\text { Time of operation } \\
\text { of up to } 4 \text { years ( } \%)\end{array}$ & 51.5 & 62.5 & 65.2 & 88.2 & 60.5 \\
\hline
\end{tabular}


the main reason reported. This percentage ranged from $49.1 \%$ (large municipalities) and $77.2 \%$ (midsize municipalities). Abandonment by parents or guardians is the second or third most frequently reported reason, depending on the size of the municipality. This percentage ranged from $12.7 \%$ (in metropolises) to $35.1 \%$ (in midsize municipalities). The high percentage of children sheltered due to the chemical dependence of their parents or guardians is also noteworthy. This percentage was $24.6 \%$ in small municipalities, $21.1 \%$ in midsize ones, $38.6 \%$ in large municipalities, and $9.7 \%$ in metropolises. Physical violence perpetrated by one or more family members against the child/adolescent is also one of the main reasons that the child or adolescent went into care, as the rates range between 10 and $14 \%$, for most municipality sizes but are as high as $19.3 \%$ among children and adolescents in care in midsize municipalities.

At the time the survey was carried out, across the country there were 791 foster families who were registered or already cared for children and adolescents. In exceptional cases, the foster families were composed of people from the extended family of the children and adolescents in shelter. Regarding the family distribution by municipality size, $35.7 \%$ of them are in small municipalities, $5.7 \%$ in midsize ones, $33.5 \%$ in large municipalities, and $25.2 \%$ in metropolises.

\section{Discussion}

In recent years, there has been a considerable expansion of social service provision in Brazil, involving the standardization and regulation of foster care provided to children and adolescents. This effort sought to address problems that arose in the decades prior to expansion, including growing demand, lon- ger stays, and multiple placements. Findings from the national survey suggest that while progress has been achieved, there are still gaps and weaknesses, reflecting this time of transition, as services gradually adapt to the national operating guidelines $(5,9,10)$. Recent public policies and the prevailing social and economic context help to explain the current situation of foster care in Brazil.

First of all, result from the survey that draws attention is the high number of children and adolescents in foster care services in Brazil, with an emphasis on institutional care. This reflects the disparity and social exclusion that many Brazilian families experience, as they suffer the effects of economic, social, and health factors that undermine their ability to care for their children (11).

This data is consistent with the most commonly reported reasons for seeking shelter, namely family neglect and abandonment, irrespective of the type of foster care. While it is important to recognize that poverty does not lead to negligence, it can be an important aggravating factor.

As a result, during the time that children and adolescents spend in foster care, professionals must build a follow up plan for the family, together with the family itself and the protection network services. This can involve the nuclear or extended family with the aim of overcoming the reasons that led to the separation of the child and adolescent and thereby targeting family reintegration. For this to occur, outcomes must focus on identifying and extending the protective capacity of the families and their ability to overcome difficulties, rather than pointing out their faults related to the current situation of the child and adolescent (1).

Regarding the profile of institutional care, the findings of this national survey point to a significant number of entities created a long time ago. These older institutions are mostly located in cities with larger population sizes, 
and tend to be non-governmental and religiously affiliated, part of a tradition of charitable provision of foster care in Brazil. It is important to highlight that the religious nature of these services is contrary to the guidelines governing their operation, which must ensure respect for the religious beliefs, habits and traditions of children, adolescents, and their families. National guidelines recommend that young people have access to religious activities, but also retain the right not to participate in religious services and to decline religious guidance that is not meaningful to them (5).

An analysis of institutional foster care services by population size allows for a discussion about places that share common attributes, thereby helping to better understand national level data and to draw up solutions and promote public policies that are specific to each demographic. Debates regarding such a strategy must take into consideration local care policies, the intersectoral network of services, quality improvements to services, professional training, the profile of the children, adolescents and their families, and the network support and social support. An analysis that only includes broader geographic factors, such as state or region, runs the risk of not considering the heterogeneity of political and sociocultural factors that influence the services and families.

Other studies that have used a similar analytic strategy have emphasized the success or failure of children after leaving the services, dependent on their location in large or small cities $(4,7,8)$. In one such study, the U.S. Department of Health and Human Services (4) suggests that cities with smaller populations tend to be more successful in this matter. This study conducted in the United States points out that the districts of Fort Lauderdale and Miami, both of which are urban areas, were the sites with the lowest rates of successful leave of the child during the period of the study, while in Gainesville and Port St. Lucie, cities with smaller populations, a higher percentage of children successfully left foster care. However, this finding contradicts the results of research carried out in the state of Tennessee, which showed that children living in care in urban cities had a $50 \%$ greater probability of leaving foster care than did children under custody in rural areas of the state (7).

The results of the Brazilian national survey do not allow for an analysis of the success or failure of children subsequent to leaving the service, but they do provide information on the density of institutional foster care in large cities and capitals, set against a lack of infrastructure for such care in less populated areas. On the other hand, there is a strong presence of transition houses in smaller cities, which can be explained by the fact that these services tend to be provided to children and adolescents in transit or to those who require an initial or emergency period of care, so that they can then be sent to the service that best meets their needs, even if it is outside of their city of origin. This is a cause for concern since it seems that the children and adolescents who need protection and live in small size municipalities tend to be forwarded to services located in larger towns and cities, which can make it difficult for the family to visit them, thereby hindering family reintegration.

Another matter of concern is how fragile the team structure can be in many service units, particularly those located in small municipalities. The work provided by the technical team and by caregivers is crucial and is based on daily care, on working with the family of origin towards reintegration, on monitoring the child or adolescent that was brought to the service, and on intersectoral partnerships (5). A lack of proper and trained human resources may be an impediment to guaranteeing the quality of services and care given to the children and adolescents. 
A positive aspect observed in Brazil is the significant decline in the length of time spent by children and adolescents in foster care services, in general, based on the recommended period of two years (1). For decades, it was not unusual to find thousands of children and adolescents in these services throughout their entire childhood and adolescence and, often, into adult life. However, given the adverse effects of institutionalization on the lives of these children and adolescents, and the great difficulty in reintegrating families after such a long time, nowadays in Brazil and in most countries, the period of stay in these foster care units has been drastically reduced for a significant number of individuals. In the U.S. between 2002 and 2012, the average length of stay declined by more than a quarter overall, from 31.3 months to 22.4 months (4).

With regard to family care services in Brazil, they tend to be incipient in nature and are more common in smaller municipalities, taking in fewer children. This practice is an alternative to institutionalization and may have more a positive effect on children and adolescents when compared with institutional care, since it offers a more individualized type of care, based on the domestic relationship model, targeting integration with the family and the community (1).

In several parts of the world, this type of care is growing (4). Certain child or adolescent profiles seem to be more suited to this model of care, including those under the age of six or up to one year of age, those who demonstrate good behavior, who find it easier to develop affection, those who are taken together with their siblings, those who are not consumers of drugs, that have no history of institutionalization and, particularly, those who have experienced a lack of affection (12).

However, the recruitment and retention of foster parents has become a critical issue. Broad social and economic changes, such as a growth in the number of working mothers and an increase in single parent families, have made the recruitment of foster parents more challenging. Moreover, although many foster parents stop fostering because they grow old and retire, many others do so because they are dissatisfied with their experiences as foster parents. U.S. foster parents are in short supply, especially in large cities: although the number of children in foster care increased by $68 \%$ between 1984 and 1995, the number of foster parents decreased by $4 \%$ (12-15).

Irrespective of the type of foster care, services need to be responsive to the needs of children and their families, and must be shaped by five key principles: (a) a family focus that perceives foster care as a service for the entire family as opposed to a service only for the child or parents; (b) a child-centered orientation that places the needs of the individual child at the forefront of case planning; (c) the delivery of services from a community-based perspective so that children remain in contact with the most important people in their lives and live in familiar surroundings; (d) developmental appropriateness so that the care and services that a child receives are commensurate with the child's age and physical, cognitive, behavioral, and emotional status; and (e) cultural awareness so that the cultural strengths and values of all families are respected and accommodated $(16,1)$. The findings of this study may encourage other specialists to study the topic, especially in developing countries, highlighting and promoting strategies that include the family, community and local specialized services that strive to build a comprehensive and responsive foster system.

\section{Conclusion}

The nationwide study in Brazil on children and adolescents in foster care points to the existence of a high number of children and 
adolescents in institutional care services, which reflects the disparity and social exclusion faced by many Brazilian families. The study calls attention to the need to establish a community approach to intervention that includes families, with the aim of prevention, and advocates a highly restricted use of residential care.

Acknowledgement: Sources of support: Ministry of Social Development, Brazil.

Authors' contributions: Conception and design: SA; Acquisition, analysis and interpretation of data: LP, SA; Drafting the manuscript: SA, JA, LP; Revising it critically for important intellectual content: SA, JA, LP.

Conflict of interest: The authors declare that they have no conflict of interest.

\section{References}

1. Assis SG, Farias LOP. National survey of children and adolescents in foster care. Sao Paulo: Hucitec; 2013.

2. National Council of the Public Ministry (Brazil). Report from the Childhood and Youth - Resolution No. 71/2011: A look at the childcare services in the country. Brasília: CNMP; 2013.

3. Del Valle JF, López ML, Boada CM, Arteaga AB. Foster care in Spain: an outcome evaluation. Madrid: Ministry of Labour and Social Affairs; 2003. p. 19-42.

4. Department of Health and Human Services (U.S.). ACYF Office of Data, Analysis, Research, and Evaluation Data Brief 2013-1. Recent Demographic Trends in Foster Care [monograph on the internet]. Washington; 2013. [cited 2014 May 5] Available from: http://www.acf.hhs.gov/sites/default/files/cb/data_brief_foster_care_trends1.pdf.

5. Brazil. Ministry of Social Development. National Council of Welfare. Resolution no. 109, November 11, 2009. Criminalization of national social services. Federal Official Gazette of Brazil, November 25, 2009; section 1.

6. United Nations Development Programme. Human Development Report 2011 Sustainability and
Equity: Better future for all [monograph on the internet]. New York: UNDP; 2011. [cited 2014 May 15] Available from: http://hdr.undp.org/sites/default/files/hdr_2011_pt_complete.pdf.

7. Becker MA, Jordan N, Larsen R. Predictors of successful permanency planning and length of stay in foster care: the role of race, diagnosis and place of residence. Child Youth Serv Rev. 2007;29(8):1102 $-13$.

8. Glisson C, Bailey JW, Post JA. Predicting the time children spend in state custody. Soc Serv Rev. 2000;74(2):253-80.

9. Brazil. Ministry of Social Development. National Plan for the Promotion, Protection and Defence of the Rights of Children and Adolescents to Family and Community Life. Brasilia: MDS; 2006.

10. Brazil. Ministry of Social Development. National Council of Welfare. National Policy for Social Services. Brasília: MDS; 2004.

11. Assis SG, Pesce, RP, Oliveira RVC, Avanci JQ. Life span-perspective- child mental health- socioeconomic inequalities and family resources. In: Bahrer-Kohler S, editor. Social Determinants and Mental Health. New York: Nova Science Publishers; 2011. p. 183-94. (Public Health in the 21st Century).

12. National Council for the Rights of Children and Adolescents (Brazil). National Council of Welfare. Technical guidance for childcare for children and adolescents. Brasília: CONANDA; 2009.

13. Barbell K, Freundlich M. Foster Care Today [monograph on the internet]. Washington: Casey Family Programs; 2001. [cited 2014 May 2] Available from: http://www.docs.lakotalaw.org/ombudsman\%20rebuttal\%20sources/foster_care_today.pdf.

14. Curtis PA, Boyd JD, Liepold M, Petit M. Child abuse and neglect: a look at the states: the CWLA stat book. Washington: Child Welfare League of America; 1995.

15. House of Representatives (U.S.). Background material and data on major programs within the jurisdiction of the Committee on Ways and Means (Green Book). Washington: U.S G.P.O.; 2000.

16. Dougherty S. Toolbox no. 2: Expanding the role of foster parents in achieving permanency. Washington, DC: Child Welfare League of America; 2001. 